\title{
An Aberrant Subclavius Posticus Muscle: A Case Report
}

\author{
Laura Grigoriță Monica-Adriana Vaida Adelina Jianu \\ Department of Anatomy and Embryology, "Victor Babeş" University of Medicine and Pharmacy, Timisoara, Romania
}

\section{Significance of the Study}

- This rare anatomic variant of the supernumerary muscle, named subclavius posticus muscle, should be taken into account while evaluating patients with thoracic outlet syndrome.

\section{Keywords}

Muscle anomaly · Aberrant subclavius posticus muscle ·

Thoracic outlet syndrome

\section{Abstract}

Objective: An aberrant subclavius posticus muscle was found during routine dissection of the left infraclavicular fossa of a 60-year-old male cadaver. Presentation: This aberrant muscle arises antero-medially, from the costoclavicular ligament, runs postero-laterally, over the trunks of the brachial plexus, and postero-lateral has a common insertion with the omohyoid muscle. Conclusion: The presence of such an aberrant muscle may cause a dynamic compression of the subclavian artery and brachial plexus.

\section{(c) 2018 The Author(s)}

Published by S. Karger AG, Basel

\section{Introduction}

The importance of the recognition and the diagnosis of the conditions affecting the vessels and the nerves at the thoracic outlet is now widely accepted [1]. The present study aims to describe the presence of an aberrant muscle which can be a possible cause of the thoracic outlet syndrome. According to its location, origin, and insertion, this muscle can be a variant of the subclavius posticus muscle. It was first reported by Rosenmüller in 1800 [2] and then described as a supernumerary muscle between the subclavius and intermediary tendon of the omohyoid muscle [2].

\section{Case Report}

During routine dissection studies for medical students, at the Department of Anatomy and Embryology, Victor Babeş University of Medicine and Pharmacy, Timisoara, a unilateral variant of the subclavius posticus muscle was found in a 60 -year-old male cadaver. During the dissection of the left infraclavicular fossa, after removing the skin and the subcutaneous tissue, we followed the clavipectoral fascia and found a ligament reinforcing the fascia and extending from the costoclavicular ligament to the coracoid process of the scapula close to the insertion of the pectoralis minor muscle (Fig. 1). In the postero-superior side of this ligament, an aberrant muscle, covered by its own fascia, measuring $12.3 \mathrm{~cm}$ in length and $1 \mathrm{~cm}$ in width was found, with an antero-medial origin on the costoclavicular ligament and postero-lateral insertion on the superior border of the scapula and on the superior transverse scapular ligament, sharing a common insertion with the inferior belly of the omohyoid muscle, extending toward the base of the coracoid process (Fig. 2). It runs under the subclavian artery, sub-

\section{KARGER}

E-Mail karger@karger.com www.karger.com/mpp
(C) 2018 The Author(s)

Published by S. Karger AG, Basel

Karger

Open access

This is an Open Access article licensed under the Creative Commons Attribution-NonCommercial-4.0 International License (CC BY-NC) (http://www.karger.com/Services/OpenAccessLicense), applicable to the online version of the article only. Usage and distribution for commercial purposes requires written permission.
Monica-Adriana Vaida

Department of Anatomy and Embryology

"Victor Babeș" University of Medicine and Pharmacy

2 Eftimie Murgu Square, RO-300041 Timisoara (Romania)

E-Mail vaida.monica@umft.ro 


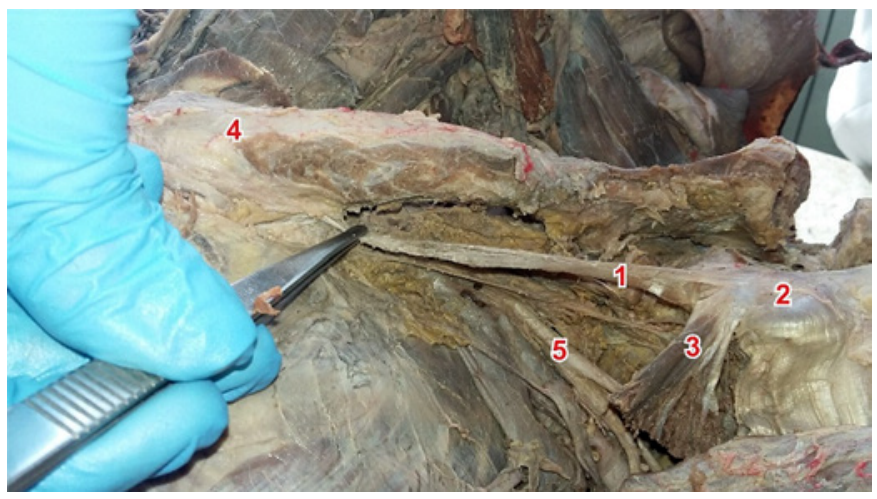

Fig. 1. Dissection revealing the left infraclavicular region and the ligament between the costoclavicular ligament and the coracoid process of the scapula. 1, Ligament extending from the costoclavicular ligament to the coracoid process of the scapula. 2, Coracoid process of the scapula. 3, Pectoralis minor muscle. 4, Sternal end of the clavicle. 5, Trunks of the brachial plexus.

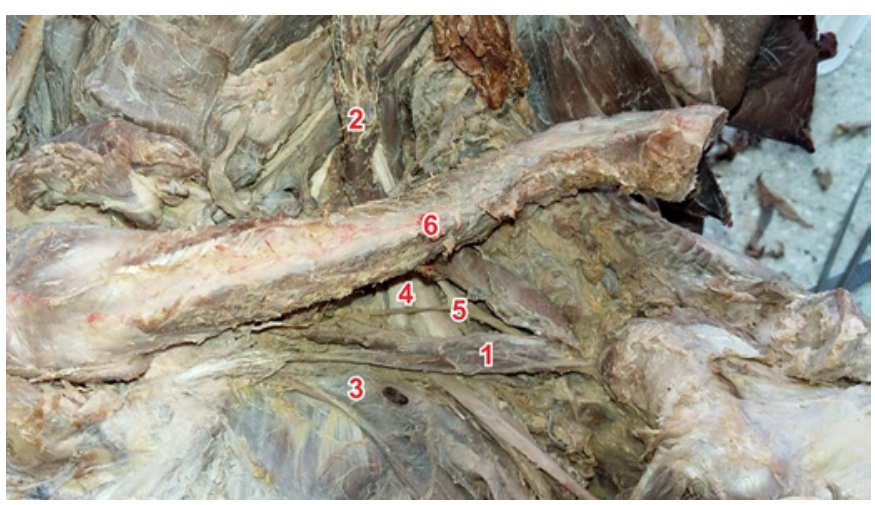

Fig. 2. Dissection revealing the aberrant subclavius posticus muscle. 1, Aberrant subclavius posticus muscle. 2, Omohyoid muscle. 3 , Subclavian vein. 4 , Trunks of the brachial plexus. 5, Suprascapular nerve. 6, Clavicle.

clavian vein, and trunks of the brachial plexus. The suprascapular nerve runs above the superior transverse scapular ligament and perforates the muscle giving its innervations. The muscle has no relation to the subclavius muscle. The omohyoid and the subclavius muscles were normal.

\section{Discussion}

Several authors have reported aberrant muscles between the clavicle and the superior border of the scapula. Most of the authors found an aberrant muscle, named subclavius posticus muscle or chondroscapularis muscle [3], with the same origin on the first costal cartilage or on the superior surface of the sternal end of the first rib [3], and variable insertion on the superior border of the scapula, mediocaudal to the inferior belly of the omohyoid [2], on the superior border of the scapula and superior transverse scapular ligament [4], on the transverse scapular ligament and coracoid process [5], on the superior angle of the scapula, on an additional ligament extending from the medial margin of the suprascapular notch and the capsule of acromioclavicular joint, and on the axillary sheath and fascia covering the subscapularis muscle [6]. Yun et al. [7] described the absence of subclavius muscle with contralateral subclavius posticus muscle in 1 case. Sato et al. (cited by Akita et al. [2]) proposed that, according to their location, origin, insertion and most important according to their innervations, these aberrant muscles can be classified in 2 categories, subclavius posticus muscle innervated by a branch from the nerve to the subclavius muscle, and a duplication of the inferior belly of the omohyoid muscle, innervated by a branch from the nerve to the inferior belly of the omohyoid muscle. Diwan et al. [6] suggested that the variation of subclavius muscle is due to anomalous differentiation of primary pectoral muscle. In the present study we describe a normal subclavius muscle and an aberrant muscle that we believe to be a variant of the subclavius posticus muscle according to its origin on the costoclavicular ligament, and its insertion on the superior border of the scapula and on the superior transverse scapular ligament, sharing a common insertion with the inferior belly of the omohyoid.

The thoracic outlet syndrome is a clinical entity with pain and discomfort in the upper limb, caused by compression of the brachial plexus, subclavian artery and/or subclavian vein in the costobrachial region, due to anomalous fibrous muscular bands, like an enlarged or an aberrant muscle, an extra rib, a rib fracture [8], or a tumor. The diagnosis is suggested by the symptoms and can require further supporting testing that include radiological examination, like standard radiography, Doppler ultrasound, angiography, CT scan, and MRI, which can show an accessory muscle [9].

\section{Conclusions}

The origin and insertion of this aberrant subclavius posticus muscle and its relation to the subclavian vessels and to the brachial plexus suggest that it might be a factor of compression and we recommend that this should be taken into account during the examination of patients with thoracic outlet syndrome [2,9-10]. 


\section{Statement of Ethics}

The research was conducted ethically in accordance with the World Medical Declaration of Helsinki.

\section{Disclosure Statement}

The authors declare that they have no conflict of interests.

\section{References}

1 Smayra T, Nabhane L, Tabet G, et al: The subclavius posticus muscle: an unusual cause of thoracic outlet syndrome. Surg Radiol Anat 2014;36:725-728.

2 Akita K, Ibukuro K, Yamaguchi K, et al: The subclavius posticus muscle: a factor in arterial, venous or brachial plexus compression? Surg Radiol Anat 2000;22:111-115.

3 Prakash S, Pai MM, Prabhu LV, Vadgaonkar $\mathrm{R}$, et al: The subclavius posticus muscle: its phylogenetic retention and clinical relevance. Int J Morphol 2006;24:599-600.
4 Forcada P, Rodriguez-Niedenfuhr M, Llusa $\mathrm{M}$, et al: Subclavius posticus muscle: supernumerary muscle as a potential cause for thoracic outlet syndrome. Clin Anat 2001;14:5557.

5 Martin MR, Vyas NM, Sedimayr JC, et al: Bilateral variation of subclavius muscle resembling subclavius posticus. Surg Radiol Anat 2008;30:171-174.

6 Diwan RK, Chopra J, Anitarani A, et al: A rare variation of subclavius muscle. J Anat Sci 2014;22:22-25.

7 Yun S, Park S, Kim CS: Absence of the subclavius muscle with contralateral subclavius posticus muscle: first imaging report. Clin Imaging 2017;16:54-57.
8 Martins RS, Siqueira MG: Case report cervical rib fracture: an unusual etiology of thoracic outlet syndrome in a child. Pediatr Neurosurg 2007;43:293-296.

9 Muellner J, Kaelin-Lang A, Pfeiffer O, et al: Neurogenic thoracic outlet syndrome due to subclavius posticus muscle with dynamic brachial plexus compression: a case report. BMC Res Notes 2015;8:351.

10 Rabi S, Madhavi C: Case reports with special reference to the innervation, development and clinical significance of the subclabvius posticus and the termination of the facial vein in South Indian cadavers. Eur J Anat 2008;12: 133-136. 